\title{
Steel Plate Shear Walls - From Research to Codification
}

\author{
Jeffrey W. Berman ${ }^{1}$, Darren Vian ${ }^{2}$, and Michel Bruneau ${ }^{3}$
}

${ }^{1}$ Ph.D. Candidate, Department of Civil, Structural, and Environmental Engineering, 212

Ketter Hall, State University of New York at Buffalo, Buffalo, NY 14260; PH (716) 6452114 x 2437; FAX (716) 645-3733; email: jwberman@eng.buffalo.edu

${ }^{2} \mathrm{Ph}$.D. Candidate, Department of Civil, Structural, and Environmental Engineering, 212 Ketter Hall, State University of New York at Buffalo, Buffalo, NY 14260; PH (716) 6452114 x 2437; FAX (716) 645-3733; email: vian@eng.buffalo.edu

${ }^{3}$ Director, Multidisciplinary Center for Earthquake Engineering Research and Professor, Department of Civil, Structural, and Environmental Engineering, 130 Ketter Hall, State University of New York at Buffalo, Buffalo, NY 14260; PH (716) 645-2114 x 2437;

FAX (716) 645-3733; email: bruneau@ mceermail.buffalo.edu

\section{Abstract}

This paper will briefly discuss some of the research that will likely be incorporated into US design codes for the use of steel plate shear wall as seismic load resisting systems. References to numerous research projects carried in the United States, Canada, and other countries will be given and their major findings highlighted. The strip model, developed by others for the representation of SPSW, is described and plastic analysis results for that model and their use in design is discussed. Finally, new directions for SPSW research, including the use of light-gauge and low yield-point steels, strategic hole placement, and reduced beam sections are described in the context of some recently completed and ongoing research.

\section{Introduction}

This paper will provide an overview of steel plate shear wall(s) (SPSW) design as these systems can be an attractive option for lateral load resisting systems in both new and retrofit construction. Prior to key research performed in the 1980's, the design limit state for SPSW was considered to be out-of-plane buckling of the infill panel. To prevent buckling, engineers designed steel walls with heavily stiffened infill plates that were not economically competitive with reinforced concrete shear walls. However, several experimental and analytical studies using both quasi-static and dynamic loading showed that the post-buckling strength of thin SPSW can be substantial (Thorburn, et al., 1983; Timler and Kulak, 1983; Tromposch and Kulak, 1987; Roberts and Sabouri-Ghomi, 1992; Sabouri-Ghomi and Roberts, 1992; Cassese et al., 1993; Elgaaly et al., 1993; Driver et al., 1998; Elgaaly and Liu, 1997; Elgaaly 1998; Rezai, 1999; Lubell et al., 2000; Berman and Bruneau, 2003a; Vian and Bruneau, 2004, Berman and Bruneau, 2004). Based on some of this research, the Canadian Standards Association steel design standard CAN/CSA S16-01 has implemented design clauses for SPSW allowed to buckle in shear and develop tension field action (CSA, 2001). 
Additional research on unstiffened steel plate shear walls has investigated the effect of simple versus rigid beam-to-column connections on the overall behavior (Caccese et al. 1993), the dynamic response of steel plate shear walls (Sabouri-Ghomi and Roberts, 1992, and Rezai, 1999), the effects of holes in the infill plates (Roberts and SabouriGhomi, 1992; Vian and Bruneau, 2004), the use of low yield point steel or light-gauge steel (Vian and Bruneau, 2004; Berman and Bruneau, 2005), and the effects of bolted versus welded infill connections, as well as other practical considerations, by Elgaaly (1998). Furthermore, finite element modeling of unstiffened steel plate shear walls has been investigated in some of the aforementioned papers as well as by Elgaaly et al. (1993), and Driver et al. (1997).

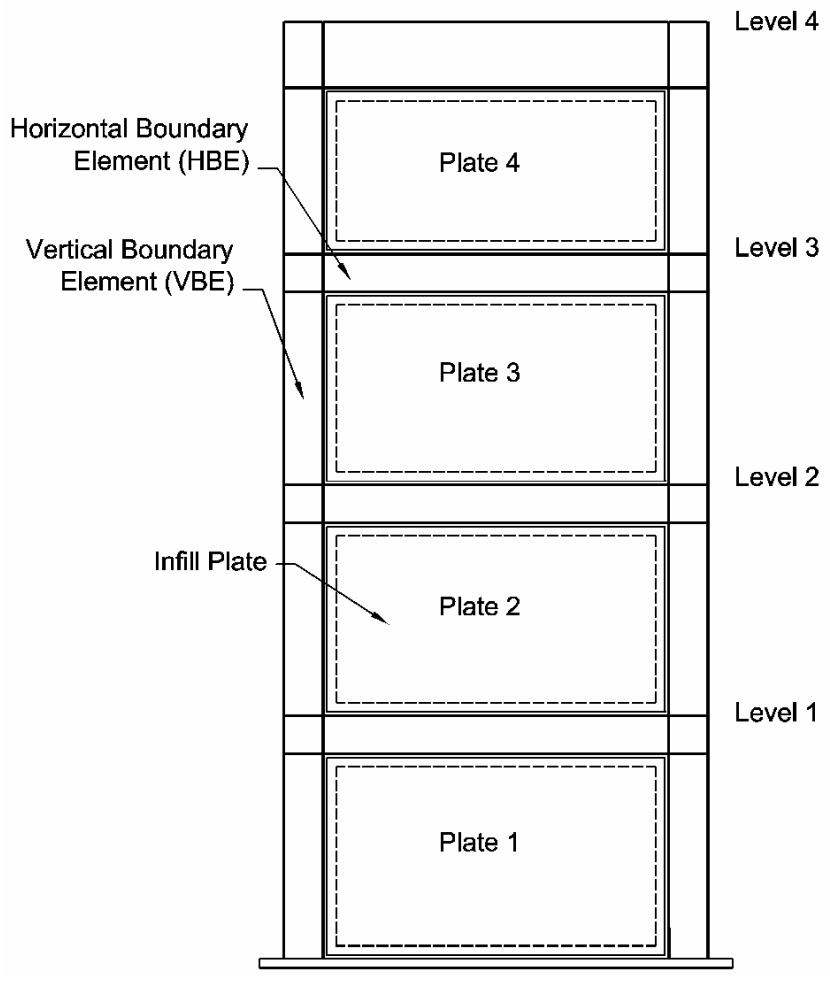

Figure 1. Typical Steel Plate Shear Wall

\section{The Strip Model Representation of SPSW}

A typical SPSW (Figure 1) consists of horizontal and vertical boundary elements (that may or may not carry gravity loads), and thin infill plates that buckle in shear and form a diagonal tension field to resist lateral loads. Based on an elastic strain energy formulation, Timler and Kulak (1983) derived the following equation for the inclination angle of the tension field, $\alpha$, in a SPSW infill plate:

$$
\alpha=\tan ^{-1} \sqrt[4]{\frac{1+\frac{t \cdot L}{2 \cdot A_{c}}}{1+t \cdot h \cdot\left(\frac{1}{A_{b}}+\frac{h^{3}}{360 \cdot I_{c} \cdot L}\right)}}
$$


where $t$ is the thickness of the infill plate, $h$ is the story height, $L$ is the bay width, $I_{c}$ is the moment of inertia of the vertical boundary element, $A_{c}$ is the cross-sectional area of the vertical boundary element, and $A_{b}$ is the cross-sectional area of the horizontal boundary element. The flexural stiffness of the horizontal boundary elements was excluded in the derivation because the opposing tension fields that develop above and below these intermediate horizontal members almost cancel out and induce little significant flexure there. Using the inclination angle given by Eq. 1, an analytical model, known as a strip model, in which the infill plates are represented by a series of pin-ended, tension only strips, was developed by Thorburn et al. (1983), and subsequently refined by Timler and Kulak (1983). A typical strip model representation of a SPSW is shown in Figure 2 and the accuracy of the strip model has been verified through comparisons with experimental results such as in Figure 3, which has been adapted from Driver et al. (1998). Note that each strip has a cross-sectional are equal to the strip's tributary width times the infill thickness.

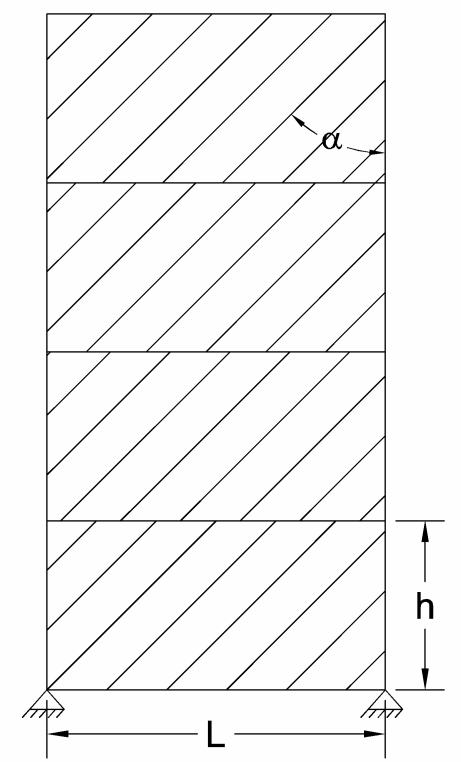

Figure 2. Strip Model Representation of a SPSW

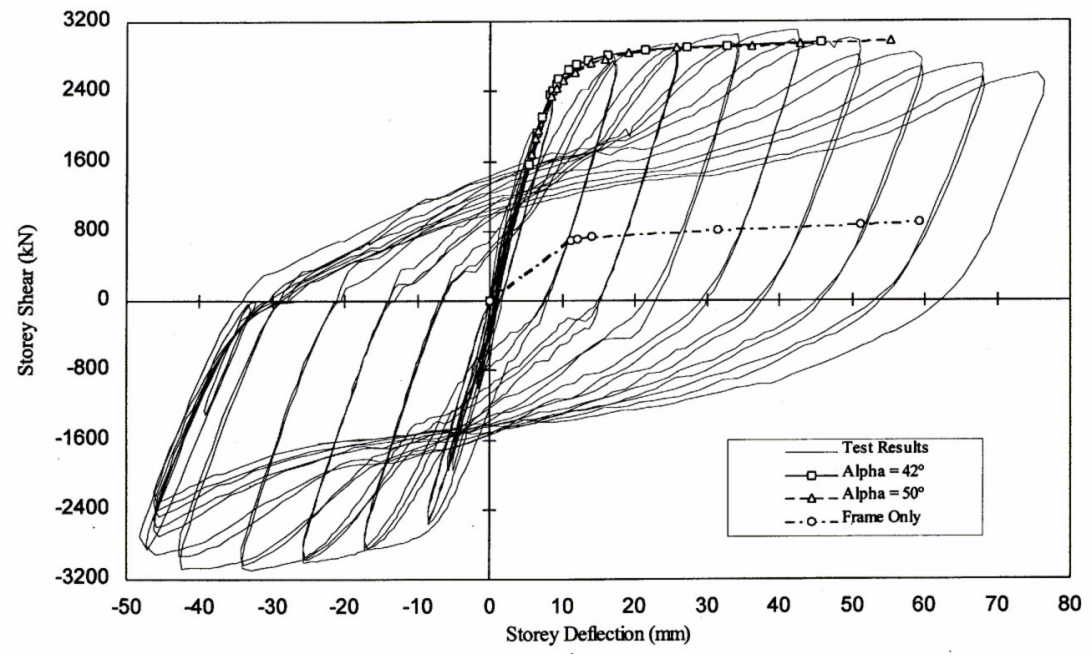

Figure 3. Comparison of Strip Model and Expeimental Results (Driver, 1998) 


\section{Plastic Analysis of SPSW}

Using the collapse mechanism of a single story SPSW in a frame with simple connections represented by the strip model, as shown in Figure 4, results in the following equation for base shear (Berman and Bruneau, 2003b):

$$
V=\frac{1}{2} \cdot F_{y} \cdot t \cdot L \cdot \sin 2 \alpha
$$

where $F_{y}$ is the infill yield stress and other terms are as previously defined.

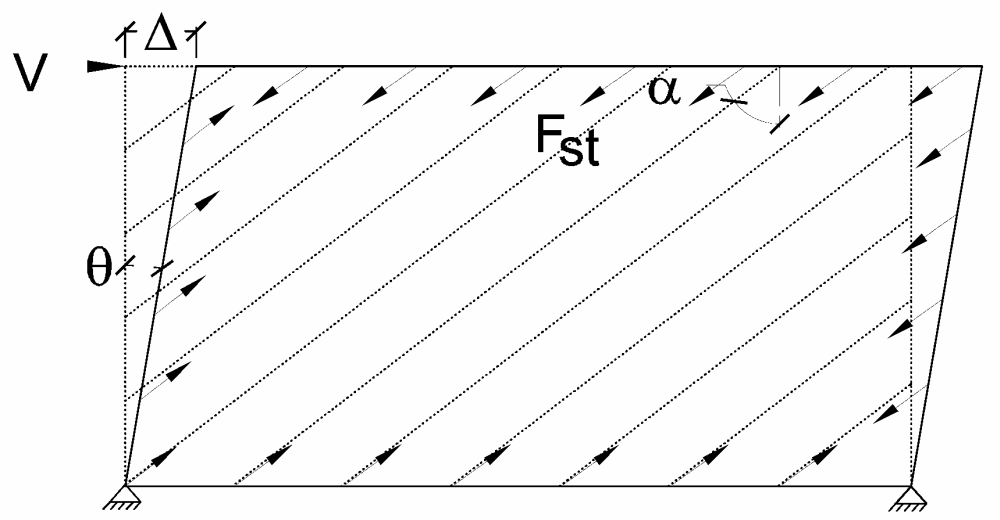

Figure 4. Single Story Collapse Mechanism

For a single-story SPSW in a frame with rigid beam-to-connections plastic analysis can again be used to find the base shear as:

$$
V=\frac{1}{2} \cdot F_{y} \cdot t \cdot L \cdot \sin 2 \alpha+\frac{4 \cdot M_{p}}{h}
$$

where $M_{p}$ is the smaller of the beam and column plastic moments. Equations are also available derived for various collapse mechanisms in multistory SPSW in Berman and Bruneau (2003b). These equations can be used to determine an infill thickness for use in development of the strip model.

\section{Other Design Issues for SPSW}

It is worthwhile to briefly mention some other design issues for SPSW which are addressed in CAN/CSA S16-01 and will likely appear in US design codes as well. Horizontal and vertical boundary elements should be designed to elastically resist development of the full expected tensile capacity of the infill plates. This ensures that the infill plate can yield in tension prior to plastic hinging of the boundary elements (providing for substantial energy dissipation in seismic applications). Such capacity design can be achieved by designing the boundary elements for the forces found from pushover analysis of the strip model, or indirectly from the procedure in CAN/CSA S1601. The connection of the infill plate to the boundary elements should also be designed for the expected tensile capacity of the infill plate and can use either a welded or bolted configuration. Four different connection details were developed, tested, and found to be equivalent by Schumacher et al. (1999). Furthermore, the vertical boundary elements 
should satisfy a minimum stiffness requirement (given in CAN/CSA S16-01) to prevent excessive deformations under the tension field action of the web plate. Finally, stiff horizontal boundary elements should be provided at the top and bottom of a SPSW to anchor the tension field.

\section{New Directions for SPSW}

One difficulty in the selection of SPSW systems is that the available panel material may be stronger or thicker than needed for a given design situation. In the perspective of capacity design, this will increase the necessary sizes of horizontal and vertical boundary members as well as foundation demands. To alleviate this concern, recent work has focused on the use of light-gauge cold-rolled and low yield strength (LYS) steel for the infill panel (Berman and Bruneau, 2005; Vian and Bruneau, 2004), and also by placement of a pattern of perforations to decrease the strength and stiffness of the panel by a desired amount (Vian and Bruneau, 2004). In addition, the use of reduced beam sections at the ends of the horizontal boundary members is being investigated as a means of reducing the overall system demand on the vertical boundary members (Vian and Bruneau, 2004).

A SPSW test specimen utilizing a light-gauge infill (thickness of $1.0 \mathrm{~mm}, 0.0396 \mathrm{in}$ ) is shown in Figure 5 (Berman and Bruneau, 2005). The specimen used W 310 x 143 (US W 12 x 96) columns and W $460 \times 128$ (US - W $12 \times 86$ ) beams. This test was performed using quasi-static cyclic loading conforming the recommended Applied Technology Council (ATC) loading protocol of ATC 24 (ATC, 1992). Hysteretic results are shown Figure 6 along with the boundary frame contribution. After subtracting the boundary frame contribution, the hysteresis of Figure 7 is obtained. This specimen reached a ductility ratio of 12 and drift of $3.7 \%$, and the infill was found to provide approximately $90 \%$ of the initial stiffness of the system. Ultimate failure of the specimen was due to fractures in the infill propagating from the welds which connected it to the boundary frame. Figures $8 \mathrm{a}$ and $8 \mathrm{~b}$ show the buckling of the infill plate at the peak displacement of cycle 20 (ductility ratio of $6,1.82 \%$ drift) and the fracture at the infill corner during cycle 26 (ductility ratio of $10,3.07 \%$ drift) respectively. 


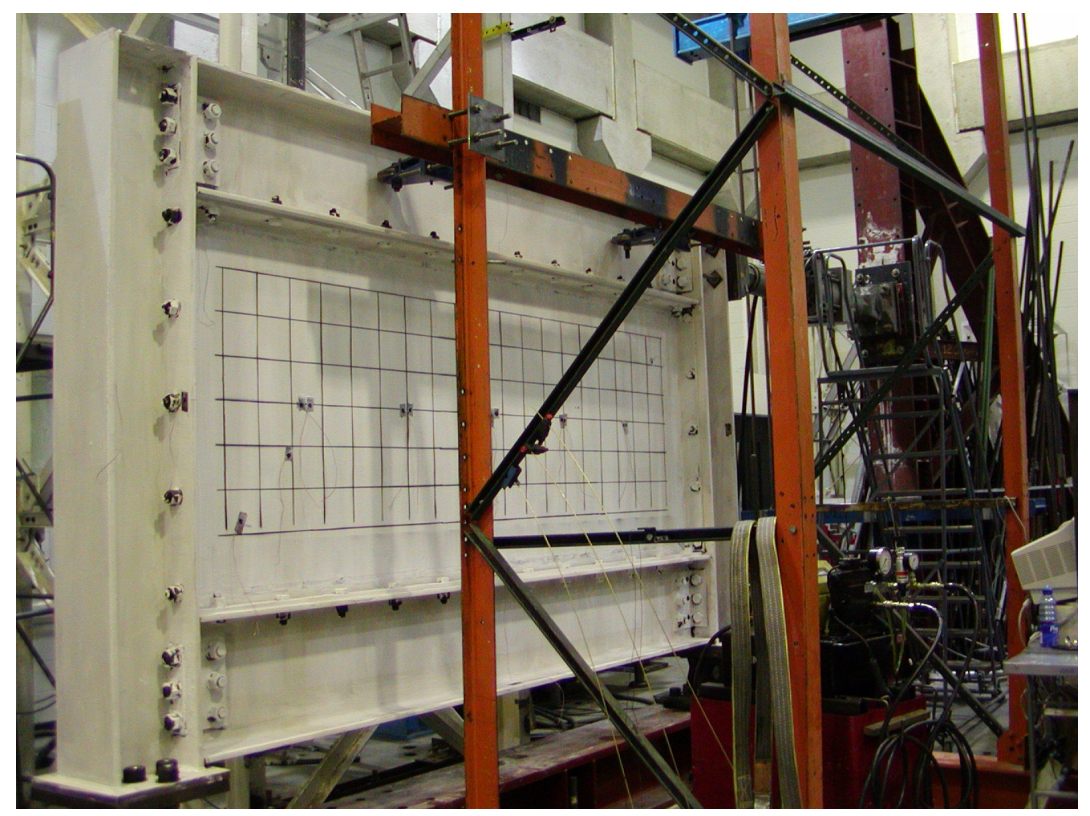

Figure 5. Light-Gauge SPSW Prior to Testing

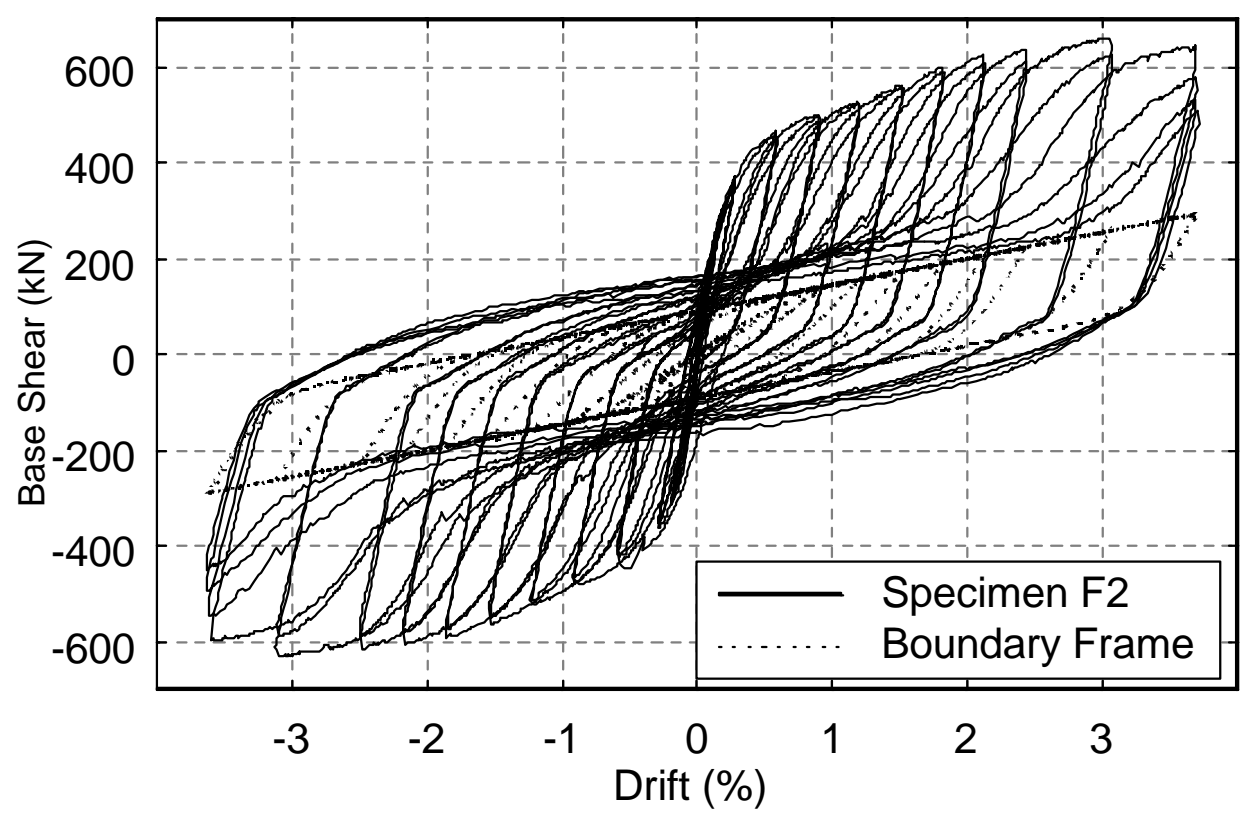

Figure 6. Light-Gauge SPSW and Boundary Frame Hystereses 


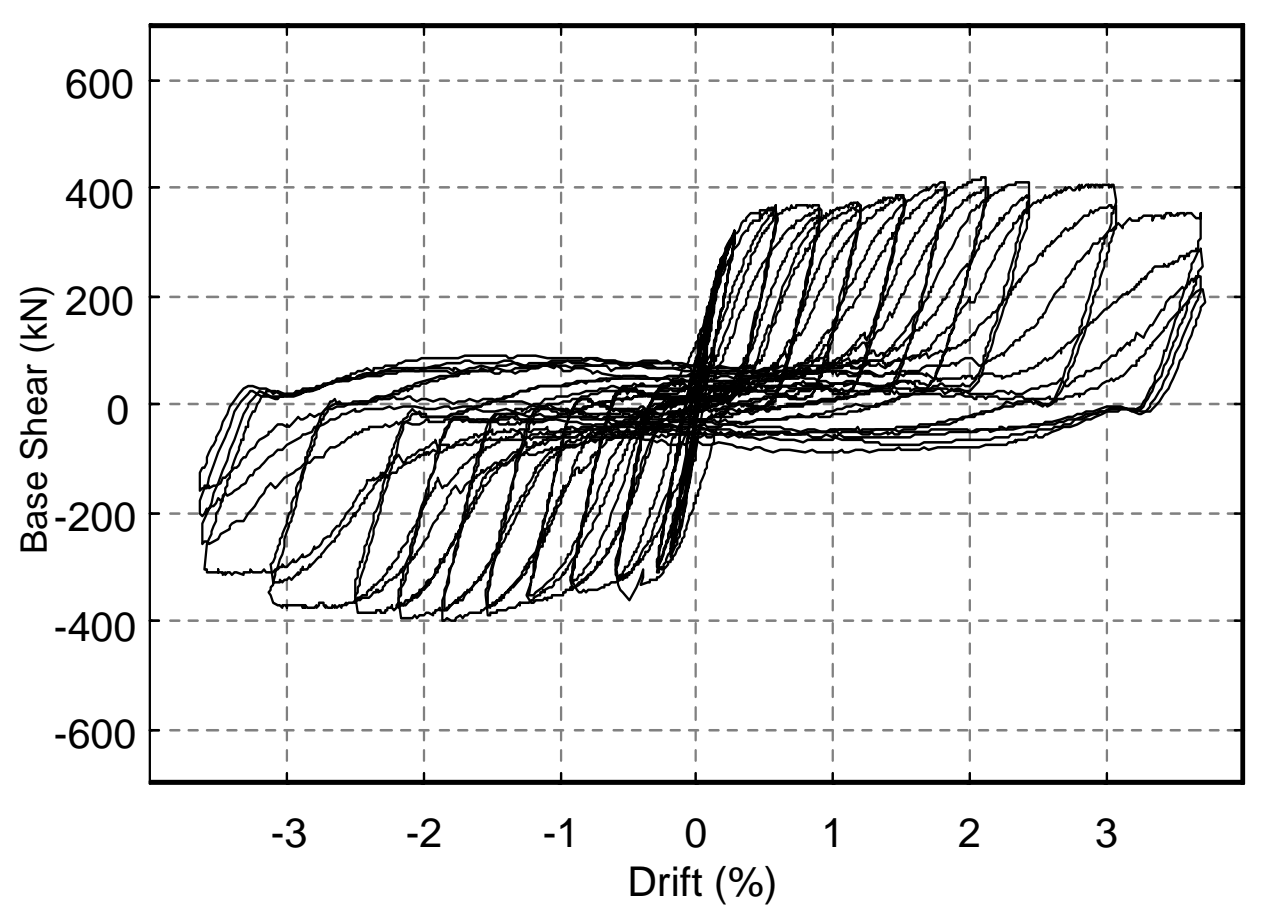

Figure 7. Light-Gauge SPSW Hystereses - Infill Only

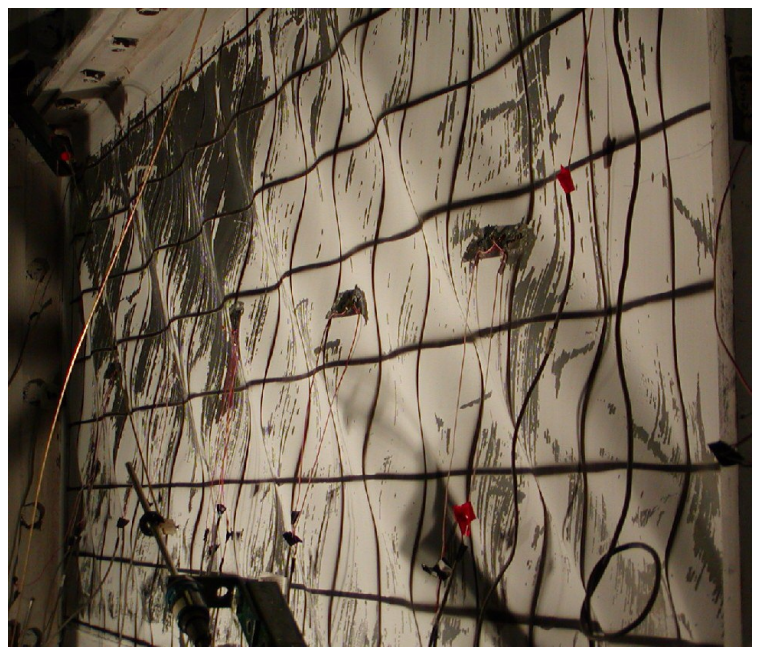

(a)

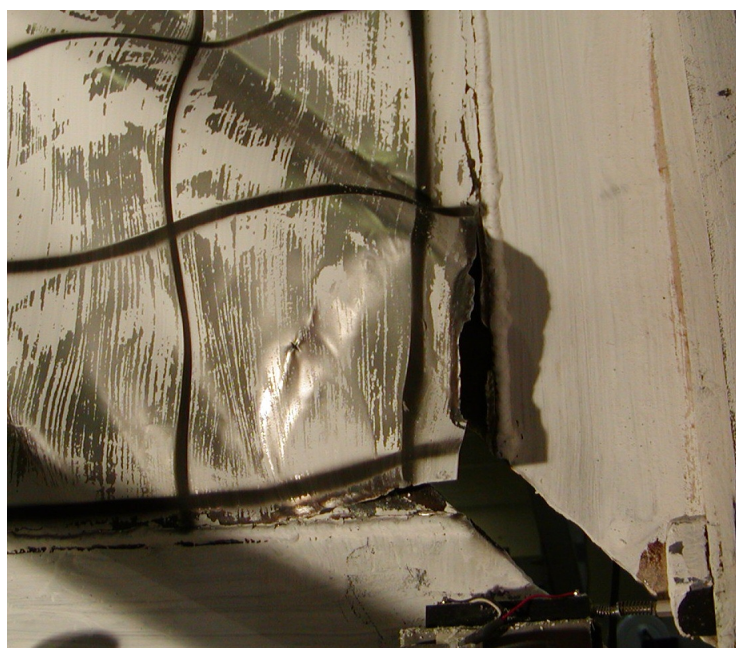

(b)

Figure 8. (a) Buckling of Infill at $1.82 \%$ Drift (b) Fracture of Infill Corner at 3.07\% Drift

Three SPSW specimens of similar size and dimension, but utilizing LYS infill panels were designed, built, and subjected to quasi-static cyclic loading (Vian and Bruneau 2004). The frames consisted of $345 \mathrm{MPa}$ steel members, while the infill panels were $2.6 \mathrm{~mm}$ thick, LYS steel plates with an initial yield strength of $165 \mathrm{MPa}$, and ultimate strength of $300 \mathrm{MPa}$, important properties that may aid in alleviating over-strength concerns mentioned above. All specimens also had beam-to-column connection details that included reduced beam sections (RBS) at each end. 
A perforated panel SPSW specimen, consisting of a panel with a total of twenty $200 \mathrm{~mm}$ diameter holes, or perforations, is shown in Figure 10 prior to testing. The multiple perforations present in the tested specimen allow for utility access in order to make the SPSW system more acceptable, while also serving as a method of reducing the panel strength and therefore the demand on the surrounding framing. This latter characteristic may prove beneficial in markets that do not have LYS readily available for structural applications.

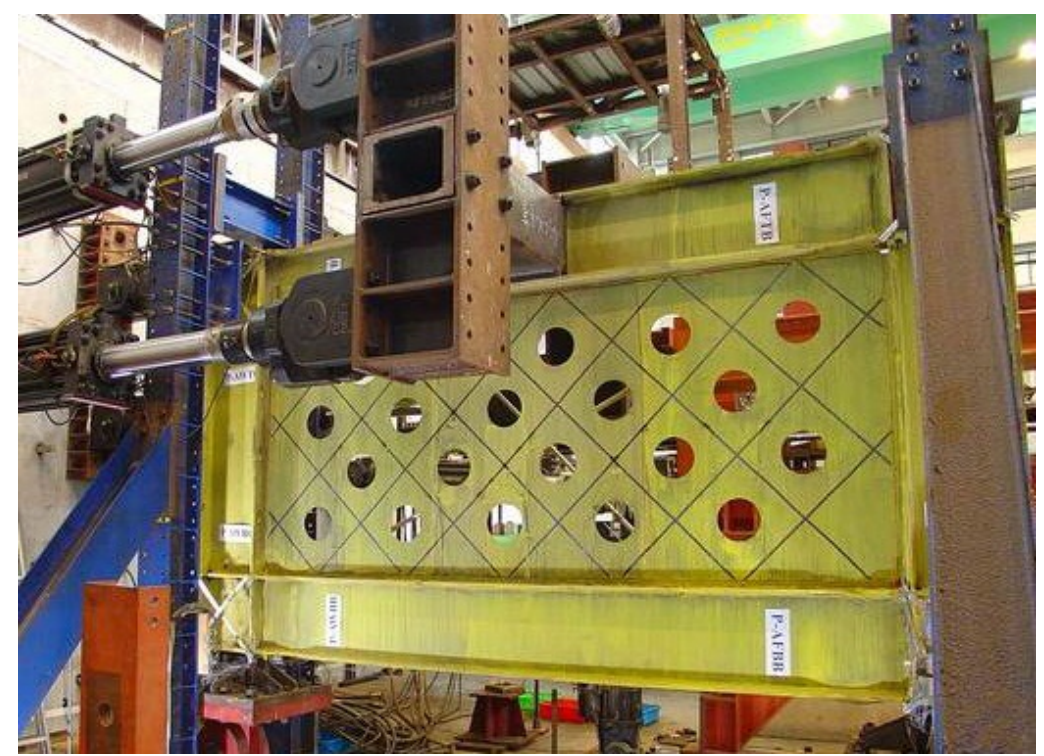

Figure 10. Perforated Panel Specimen (P) before testing

All specimens tested in this experimental program exhibited stable force-displacement behavior, with very little pinching of hysteresis loops until the significant accumulation of damage at large drifts. Specimen $\mathrm{P}$ performed well, behaving elastically at small displacements and exhibiting stable hysteretic behavior. The stiffness and strength were both reduced, as anticipated, from the solid panel specimen values, as shown in Figure 11 below.

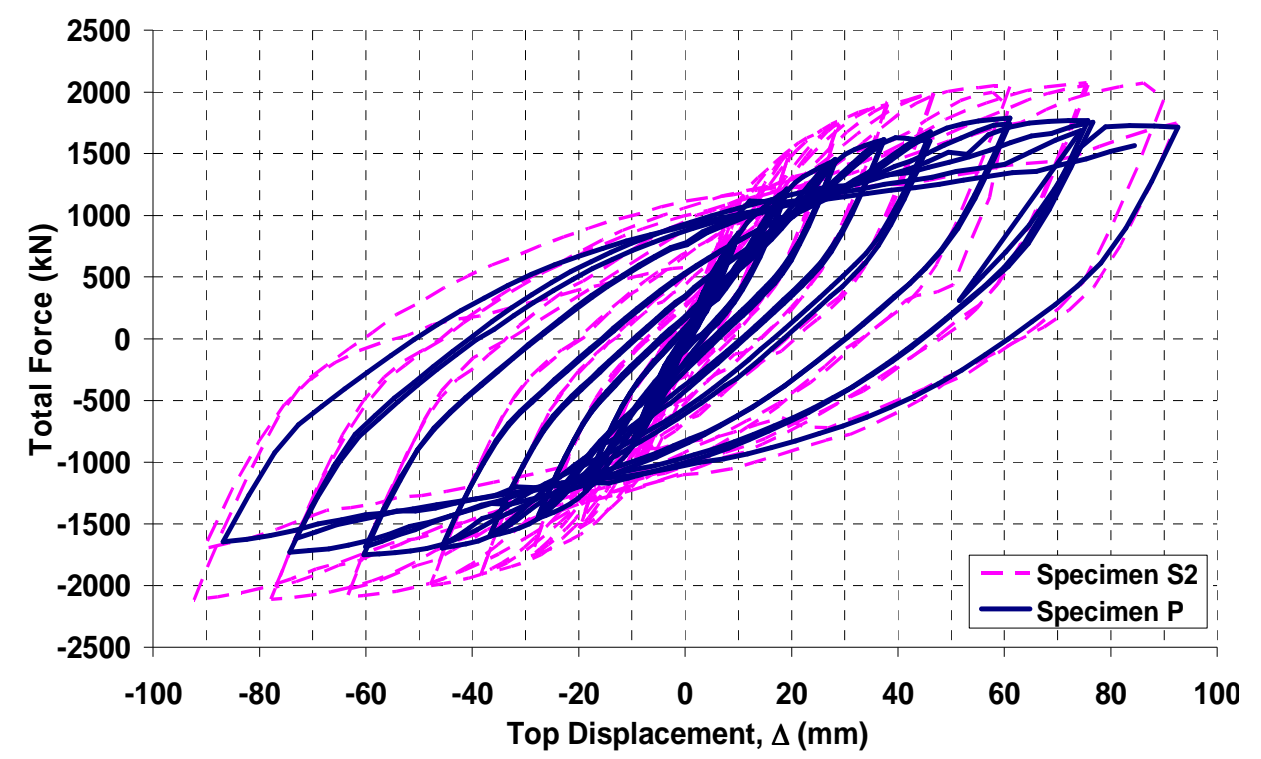

Figure 11. Solid Panel (S2) and Perforated Panel (P) Specimen Hysteresis Curves 


\section{Summary}

An overview of the use of steel plate shear walls in new and retrofit building construction has been provided. The strip model, developed by others for the representation of SPSW has been described and plastic analysis results for that model and their use in design has been discussed. Additional design considerations likely to appear in US design codes have also been presented. Finally, new directions for SPSW research including the use of light-gauge and low yield-point steels, strategic placement of perforations in the infill panel, and reduced beam sections have been described in the context of some ongoing research.

\section{Acknowledgements}

This work was supported in part by the Earthquake Engineering Research Centers Program of the National Science Foundation under Award Number ECC-9701471 to the Multidisciplinary Center for Earthquake Engineering Research. However, any opinions, findings, conclusions, and recommendations presented in this paper are those of the authors and do not necessarily reflect the views of the sponsors.

\section{References}

ATC (1992), Guidelines for Seismic Testing of Components of Steel Structures, Applied Technology Council, Report 24.

Berman, J. W., and Bruneau, M. (2003a), "Experimental Investigation of Light-Gauge Steel Plate Shear for the Seismic Retrofit of Buildings", Technical Report No. MCEER-03-0001, Multidisciplinary Center for Earthquake Engineering Research, Buffalo, NY.

Berman, J. W., and Bruneau, M. (2003b), "Plastic Analysis and Design of Steel Plate Shear Walls", Journal of Structural Engineering, ASCE, Vol. 129, No. 11, pp 1448-1456.

Berman, J. W., and Bruneau, M. (2004) "Steel Plate Shear Walls are Not Plate Girders," Engineering Journal, AISC, Vol.41, No.3, pp.95-106.

Berman, J.W., and Bruneau, M. (2005), "Experimental Investigation of Light-Gauge Steel Plate Shear Walls", Journal of Structural Engineering, ASCE, in press, accepted 5/04, scheduled for 2/05.

Caccese, V., Elgaaly, M., and Chen, R., (1993), "Experimental Study of Thin Steel-Plate Shear Walls Under Cyclic Load", Journal of Structural Engineering, ASCE, Vol. 119, No. 2, Feb. 1993, pp. 573-587.

CSA, (2001), Limit States Design of Steel Structures, CAN/CSA S16-01, Canadian Standards Association, Willowdale, Ontario, Canada.

Driver, R.G., Kulak, G.L., Kennedy, D.J.L., and Elwi, A.E. (1998), “Cyclic Test of FourStory Steel Plate Shear Wall”, Journal of Structural Engineering, ASCE, Vol. 124, No. 2, Feb. 1998, pp 112-130.

Elgaaly, M. (1998), "Thin Steel Plate Shear Walls Behavior and Analysis", Thin Walled Structures, Vol. 32, pp. 151-180. 
Elgaaly, M., Caccese, V., and Du, C. (1993), "Postbuckling Behavior of Steel-Plate Shear Walls Under Cyclic Loads", Journal of Structural Engineering, ASCE, Vol. 119, No. 2, Feb. 1993, pp. 588-605.

Elgaaly, M., and Lui, Y. (1997), "Analysis of Thin-Steel-Plate Shear Walls", Journal of Structural Engineering, ASCE, Vol. 123, No. 11, Nov. 1997, pp 1487-1496.

Lubell, A.S., Prion, H.G.L., Ventura, C.E., and Rezai, M. (2000), "Unstiffened Steel Plate Shear Wall Performance Under Cyclic Loading", Journal of Structural Engineering, ASCE, Vol. 126, No.4, pp. 453-460.

Rezai, M. (1999), "Seismic Behavior of Steel Plate Shear Walls by Shake Table Testing", Ph.D. Dissertation, University of British Columbia, Vancouver, British Columbia, Canada.

Roberts, T.M., and Sabouri-Ghomi, S. (1992), "Hysteretic Characteristics of Unstiffened Perforated Steel Plate Shear Walls", Thin Walled Structures, Vol. 14, pp. 139151.

Sabouri-Ghomi, S., and Roberts, T.M. (1992), "Nonlinear Dynamic Analysis of Steel Plate Shear Walls Including Shear and Bending Deformations", Engineering Structures, Vol. 14, No. 3, pp. 309-317.

Schumacher, A., Grondin, G.Y., and Kulak, G.L., "Connection of Infill Panels in Steel Plate Shear Walls", Canadian Journal of Civil Engineering, Vol. 26, No. 5, pp. 549-563.

Thorburn, L.J., Kulak, G.L., and Montgomery, C.J. (1983), "Analysis of Steel Plate Shear Walls", Structural Engineering Report No. 107, Department of Civil Engineering, Universtiy of Alberta, Edmonton, Alberta, Canada.

Timler, P.A. and Kulak, G.L. (1983), "Experimental Study of Steel Plate Shear Walls", Structural Engineering Report No. 114, Department of Civil Engineering, University of Alberta, Edmonton, Alberta, Canada.

Tromposch, E.W., and Kulak, G.L. (1987), "Cyclic and Static Behaviour of Thin Panel Steel Plate Shear Walls", Structural Engineering Report No. 145, Department of Civil Engineering, University of Alberta, Edmonton, Alberta, Canada.

Vian, D., and Bruneau, M. (2004), "Testing of Special LYS Steel Plate Shear Walls", Proceedings of the $13^{\text {th }}$ World Conference on Earthquake Engineering, Paper No. 978, Vancouver, British Columbia, Canada, August 1-6, 2004. 